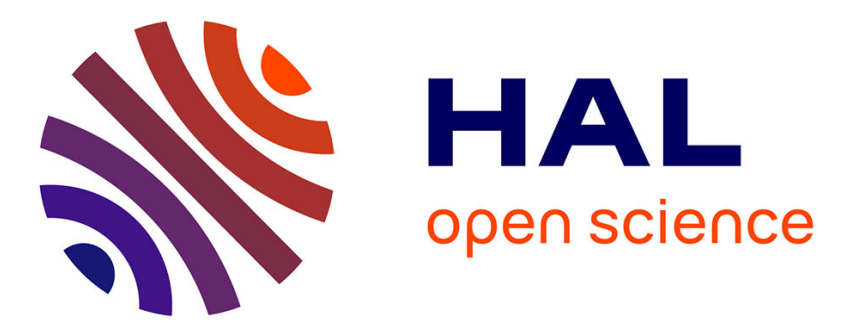

\title{
The Thermal Evolution of a Barium Ferrite Precursor Obtained by a New Chemical Coprecipitation Method
}

\author{
S. Jacobo, M. Blesa
}

\section{To cite this version:}

S. Jacobo, M. Blesa. The Thermal Evolution of a Barium Ferrite Precursor Obtained by a New Chemical Coprecipitation Method. Journal de Physique IV Proceedings, 1997, 07 (C1), pp.C1-319C1-320. 10.1051/jp4:19971126 . jpa-00254768

\section{HAL Id: jpa-00254768 https://hal.science/jpa-00254768}

Submitted on 1 Jan 1997

HAL is a multi-disciplinary open access archive for the deposit and dissemination of scientific research documents, whether they are published or not. The documents may come from teaching and research institutions in France or abroad, or from public or private research centers.
L'archive ouverte pluridisciplinaire HAL, est destinée au dépôt et à la diffusion de documents scientifiques de niveau recherche, publiés ou non, émanant des établissements d'enseignement et de recherche français ou étrangers, des laboratoires publics ou privés. 


\title{
The Thermal Evolution of a Barium Ferrite Precursor Obtained by a New Chemical Coprecipitation Method
}

\author{
S.E. Jacobo and M.A. Blesa**** \\ Facultad de Ingenieria, Universidad de Buenos Aires, Paseo Colón 850 Buenos Aires, Argentina \\ * Unidad de Actividad Quimica, Comisión Nacional de Energía Atomica, Av. Libertador 8250, \\ 1429 Buenos Aires, Argentina \\ ** INQUIMAE, Facultad de Ciencias Exactas y Naturales, Universidad de Buenos Aires, Argentina
}

\begin{abstract}
The evolution during thermal treatment of the precursor obtained by a new method to synthezise barium hexaferrite by chemical coprecipitation is described; the method involves the precipitation froma strongly alkaline ferrate(VD) solution containing barium chloride. Barium hexaferrite may be formed by heating of the original superparamagnetic precursor at temperatures as low as $700^{\circ} \mathrm{C}$ as shown by XRD, Mössbauer spectra and DTA-TGA behaviour. The precursor does not contain appreciable amounts of carbonate, thus favouring the formation of the hexaferrite at lower temperatures. Scanning electron microscopy shows that the ferrite particles are less than $0.5 \mu \mathrm{m}$ in diameter.
\end{abstract}

\section{INTRODUCTION}

The traditional synthetic procedure for barium hexaferrite, $\mathrm{BaO} .6 \mathrm{Fe}_{2} \mathrm{O}_{3}$, involves the solid state reaction of barium carbonate and hematite at $1200^{\circ} \mathrm{C}$. The reaction proceeds through the formation of several intermediate phases, such as $2 \mathrm{BaO} . \mathrm{Fe}_{2} \mathrm{O}_{3}, \mathrm{BaO} \mathrm{Fe}_{2} \mathrm{O}_{3}$ and $\mathrm{BaO} .2 \mathrm{Fe}_{2} \mathrm{O}_{3}$ and $\mathrm{BaO} .6 \mathrm{Fe}_{2} \mathrm{O}_{3}[1-3]$. Other problems are the large crystal size and crystal strains, that lowers the coercitivity. Wet synthetic procedures usually involve the coprecipitation of ferrihydrite, or amorphous ferric hydrous oxide, and barium hydroxide, followed by calcination to relatively low temperatures. Under these conditions, $\mathrm{BaFe}_{12} \mathrm{O}_{19}$ is formed at a relatively low temperatures and heating at $925^{\circ} \mathrm{C}$ leads to a highly coercive barium ferrite [4-5]. In this paper we describe the characteristics of barium hexaferrite synthesized by a procedure described by us [6], that involves coprecipitation of a precursor from a strongly alkaline solution in the presence of an oxidant (sodium hypochlorite) to generate ferrate(VI) species.

\section{EXPERIMENTAL}

\subsection{Synthesis of the precursor}

The procedure was described earlier [6]. $\mathrm{Fe}\left(\mathrm{NO}_{3}\right)_{3} .9 \mathrm{H}_{2} \mathrm{O}$ was added to an approximately $3 \mathrm{M}$ solution of sodium hypochlorite ( also $3 \mathrm{M}$ in NaCl ) to yield a $0.55 \mathrm{M}$ iron solution. $\mathrm{BaCl}_{2}, 2 \mathrm{H}_{2} \mathrm{O}$ was added to the filtered deep purple ferrate solution in adequate amounts to reach the desired $\mathrm{Ba}: \mathrm{Fe}$ ratio. The mixture evolved rapidly into a slurry, with strong oxygen evolution. The slurry was left standing for $24 \mathrm{~h}$, further treated at $80^{\circ} \mathrm{C}$ for one hour, and left in storage at room temperature. Aliquots were filtered through fritted glass, rinsed several times with $\mathrm{H}_{2} \mathrm{O}: \mathrm{C}_{2} \mathrm{H}_{5} \mathrm{OH}(50: 50)$ to remove residual chloride, and $\left(\mathrm{C}_{2} \mathrm{H}_{5}\right)_{2} \mathrm{O}$ to remove alcohol. The solid was left overnight in an oven at $110^{\circ} \mathrm{C}$.

\subsection{Thermal treatement and characterization of the solid.}

The evolution of the solid upon thermal treatment was followed by thermogravimetry, differential thermal analysis, X-Ray Diffraction (XRD), scanning electron microscopy (SEM), Fourier Transform Infrared Spectroscopy, and Mossbauer spectroscopy. The instruments used for characterization were a Mettler TA 3000 Thermoanalyzer, a RIGAKU 0-20 X-Ray Powder Diffractometer $\left(\mathrm{Cu}_{k} \alpha=1.54 \mathrm{~A}\right)$, 
a PHII IPS SEM model 515 with an EDS probe, a Nicolet FTIR apparatus, and a conventional ${ }^{57} \mathrm{Fe}$ Mossbauer transmission equipment (ELSCENT), using the constant aceleration method. Fe and Ba were determined by atomic absorption spectrometry. All reagents were analytical grade.

\section{RESULTS}

The X-ray diffractogram of the solid obtained after overnight drying at $110^{\circ} \mathrm{C}$ suggests the presence of crystalline $\mathrm{Ba}(\mathrm{OH})_{2} \cdot 2 \mathrm{H}_{2} \mathrm{O} . \mathrm{EDS}$ shows that, within the sampling volume of the technique $\left(\sim 1 \mu \mathrm{m}^{3}\right)$, the composition is homogeneous and constant; washing removes all $\mathrm{NaCl}$ sen in the original samples. The mixture obtained is an excellent precursor for $\mathrm{BaO} .6 \mathrm{Fe}_{2} \mathrm{O}_{3}$. After six hours treatment at $710^{\circ} \mathrm{C}$, the most intense diffraction peaks are already due to the hexagonal ferrite, although unreacted barium oxide is still present. Figure $\mathrm{I}$ shows that heating at $800^{\circ} \mathrm{C}$ for six hours produces highly crystalline pure barium hexaferrite. The stoichiometric solid is best obtained when a slight barium excess is used in the original solution; the excess barium remains dissolved. $\mathrm{BaO}$ from unreacted $\mathrm{Ba}(\mathrm{OH})_{2} \cdot 2 \mathrm{H}_{2} \mathrm{O}$ is still teiected in the solid sintered at $710^{\circ} \mathrm{C},{ }^{2} \cdot$ it dissapears upon further heating at higher temf ${ }^{*}$ atures. SEM examination of the precursor, and of the solid obtained by heating : $300^{\circ} \mathrm{C}$ for six hours show the evolution of the $\mathrm{Ba}(\mathrm{OH})_{2}$ platelets to barium hexaferrite single crystal particles; the good crystallinity und particle size range are adequate for good magnetic properties. Fig. 2 shows the hysteresis curve. The Mossbauer spectra of samples calcined at different temperatures, in the range $110-800^{\circ} \mathrm{C}$ show the evolution from a superparamagnetic material to the typical hexaferrite pattern of four sextuplets due to the $\left(2 a+4 f_{1}\right), 12 k, 4 f_{2}$ and $2 b$ iron ions. The resolution of the peaks and the hf parameters demonstrate that already at $700^{\circ} \mathrm{C}$, well crystallized barium hexaferrite forms. FTIR spectra of the precursors and of a thermally treated sample demonstrates that carbonate contents is very low, as expected if due precautions are taken to protect the solutions from contact with air.

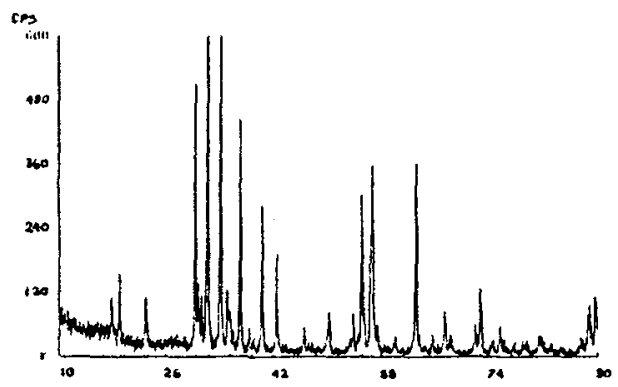

Figure 1: XR diffractogram of the synthesized hexaferrite

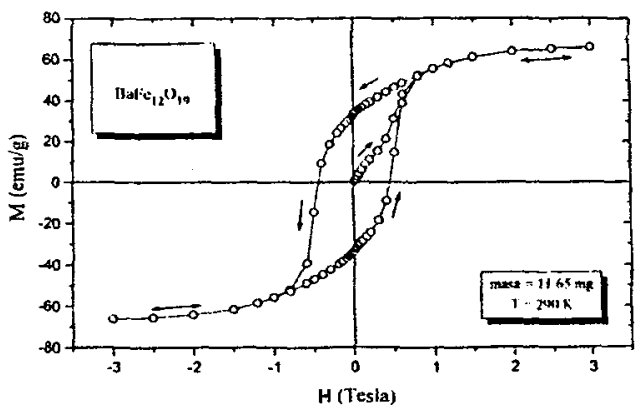

Figure 2: Hysteresis curve

\section{DISCUSSION}

The amorphous iron oxide obtained in our conditions is ferrihydrite, which is known to be structurally related to the hexagonal iron oxides such as $\alpha \mathrm{Fe}_{2} \mathrm{O}_{3}$. The structural similarity with $\mathrm{Ba}$-hexaferrite, and the intimate mixture with barium hydroxide platelets, makes easy the evolution to the ferrite. The use of a strongly oxidant alkaline solution, largely enhances iron solubility, and permits to precipitate simultaneously both ions. The hexaferrite is the only detected mixed oxide in the thermally treated samples, and the Mossbauer spectra demonstrate that $700^{\circ} \mathrm{C}$ suffices to produce it, well below the temperature of $925^{\circ} \mathrm{C}$ used by Ross [5]. The evolution from stperparamagnetism to ferrimagnetism takes place at surprisingly low temperatures; a detailed study of the site occupancies as a function of temperature is underway. DTA studies shows that the exothermic peak, characteristic of hexaferrite crystallization is centered at $730^{\circ} \mathrm{C}$, when the heating rate is $6 \mathrm{~K} \mathrm{~min}^{1}$ (sample mass, ca. $50 \mathrm{mg}$ ). The absence of carbonate is probably responsible for the high reactivity of barium.

\section{Acknowledgements}

To UBA for support through Grant Ex-056. To H.Sirkin for support and encouragement to S.E.Jacobo. To M.Tudino for AAS measurements. TOM. Villegas for SEM and EDS measurements. To A.Esteban for the DTA-TGA measurements.

\section{References}

1. Okazaki T., Kubota T., Mori S., Nat. Tech.Rept.Japan 1 (1955) 23-30.

2. Erchak M.,Fankuchen J.I., Ward R., J.Amer.Chem.Soc. 68 (1946) 2085-2096.

3. Goto Y., Takada T., J.Amer.Ceram. Soc. 143 (1960) 150-153.

4. Haneda K., Miyakawa C., Kojima H., J.Amer.Ceram.Soc. 57 (1974) 354-357.

5. Ross W., J. Amer.Ceram. Soc. 63 (1980) 601-603.

6. Jacobo S.E., Domingo-Pascual C., Rodriguez-Clemente R., Blesa M.A., J.Mater. Science, in press. 